\title{
Uma certa escuta da cidade - práticas musicais entre cubanos em São Paulo
}

\section{A certain listening of the city - musical practices among cubans in São Paulo}

Simone Luci

Professora titular do PPG Comunicação e Cultura Midiática da UNIP. Atualmente realiza pósdoutorado no Programa de Investigación em Ciencias Sociales, Niños e Juventud da Red CLACSO de Posgrados. Pesquisadora do Centro de Estudos em Música e Mídia (MUSID- ECA/USP). -

Resumo: Este artigo apresenta aspectos da pesquisa de Pós-Doutorado Sênior finalizado em 2013 (PPG Música - UNIRIO, com apoio financeiro da FAPERJ) que versou sobre a escuta do bolero entre imigrantes cubanos em São Paulo. Abordarei num primeiro momento a reflexão feita sobre música romântica e entretenimento. Em seguida, encaminho uma discussão sobre a metodologia utilizada na pesquisa: a etnografia em locais de encontros dos imigrantes; entrevistas que trazem narrativas sobre a escuta, levando em conta as formas de dar sentido às identidades pelas cançóes; análise das redes midiáticas utilizadas pelos imigrantes, onde o entretenimento é um mediador de redes de solidariedade e estratégias de visibilidade. Compreende-se a escuta musical, assim, como porta de entrada para conhecer aspectos mais amplos da experiência migrante e da cultura midiática em metrópoles globais.

Palavras-chave: Migração; Música; Entretenimento.

Abstract: This article presents aspects of senior postdoctoral research finalized in 2013 (Music Departament - UNIRIO, with financial support from FAPERJ) that expounded about the bolero listening among Cuban immigrants in São Paulo. First, we will discuss the reflection made about romantic music and entertainment. Then, we discuss the methodology used in the research: ethnography in meeting places for immigrants; interviews that bring self narratives produced by the listeners, aiming as fruitful tool for understanding their listening; analysis of media networks used by immigrants where entertainment is a mediator of solidarity networks and visibility strategies. I undestand the musical listening, like a key to interpret ampler questions of the everyday life and others aspects of the immigrant experience and the media culture in global metropolises. Keywords: Migration; Music; Entertainment. 
Canções que falam de amor e dos sentimentos ligados às relaçóes amorosas vêm despertando o interesse e atenção de estudiosos de variadas áreas do conhecimento. Mesmo que muitas vezes ainda sejam encaradas como mera distração, reforçadoras de ideologias patriarcais, bregas, cafonas ou kitschs, as cançôes chamadas românticas parecem revelar aspectos não apenas das culturas a que estão atreladas, como também elementos mais amplos da escuta e das apropriaçóes variadas que os ouvintes fazem delas (1).

Martin Stokes (2010), em seu trabalho mais recente sobre a música popular na Turquia, focaliza três populares intérpretes do país nos últimos cinquenta anos, analisando as relaçóes entre música, política e emoçóes para compreender a forma como estes três artistas tornaram-se ícones nacionais. Embora não desmereça o talento musical, Stokes argumenta que as letras cantadas por eles e suas personalidades ativam aspectos emocionais no público, acionando reconhecimentos e identificações, tornando-se vozes de intimidade cultural (cultural intimacy). Sua discussão aborda esses cantores e suas cançôes icônicas como um texto através do qual se pode compreender complexas narrativas e imaginários da nação, articuladas a questôes sobre a modernidade e a vida pública na Turquia (tais como as transformaçóes advindas do neoliberalismo e a globalização das cidades). Em trabalhos como este, cançóes que falam de emoçóes, amor e sentimentalismo revelam-se em seu caráter político, nos variados sentidos que esta palavra pode abranger.

Em outro sentido, mas ainda articulado ao caráter político, expressam também caminhos e sentidos de uma certa cultura do entretenimento, em que não apenas figuram cançôes solares, alegres e dançantes, mas também as que falam do amor, da perda, dos descaminhos dos percursos amorosos. Edgar Morin já nos anos 1960 apontava para o fato de que a Modernidade ocidental e a cultura de massas traziam, entre outras coisas, um processo de formação não só das camadas médias, mas de um padrão médio de consumo e de estilo de vida em que as massas urbanas passariam a ter acesso a um novo padrão de vida, entrando cada vez mais no universo do bem-estar, lazer e consumo, antes prerrogativa das classes altas (MORIN, 1976). No decorrer do século $\mathrm{XX}$, o desenvolvimento do trabalho assalariado e as facilidades trazidas pela tecnologia, possibilitaram ao homem um menor tempo de trabalho e, consequentemente, um maior tempo para o lazer e para a vida privada, gerando um alto grau de individualização das pessoas. Em outras palavras, "a seiva da vida encontra novas irrigaçôes fora do trabalho. As vivências vão se refugiar no lazer e vão acentuar o movimento mais geral no sentido da vida privada” (MORIN, 1976, p.89). Desta maneira, vai se compreendendo o desenvolvimento da cultura de massas também em função das necessidades individuais que emergiam, fornecendo à vida privada as imagens e modelos aspirados pelos sujeitos. Estas aspiraçôes, não podendo ser satisfeitas na racionalidade das grandes cidades, necessitariam da evasão trazida pela cultura de massas, na procura por um universo imaginário da realização, liberdade, amor e felicidade.

Os teóricos da Escola de Frankfurt já apontavam para esta questão ainda na década de 1930/40. Mas para além de uma dialética negativa ali proposta 
- em que se pensa a cultura de massas como possuidora de uma "ideologia intrínseca", alienando os indivíduos e mascarando o real - procura-se aqui enxergar na cultura de massas um componente do imaginário humano. E mais, pensar o entretenimento como elemento integrante da vida contemporânea, visto que já há constructos teóricos que pensam para além da noção de cultura de massas, que incorporam não apenas a questão do lazer, tempo livre e a questão lúdica própria ao ser humano - o que já tem sido analisado por estudos de cunho mais sociológico (2) - mas a articulação fundamental com a cultura midiática, acionando o debate dentro do campo da Comunicação. Como lembra Trigo (2003) - que realizou estudo sobre o entretenimento em seus aspectos econômicos e culturais - não se pode mais pensar separadamente o tempo do trabalho do tempo do lazer de maneira rígida, como no início da Modernidade, mas numa realidade pós-industrial atual em que estes campos se encontram embaralhados e em que a diversão está imbricada em muitos aspectos da vida, tornando-se uma parte significativa da existência, sob a forma de esporte, cultura, turismo ou educação, sendo o entretenimento um componente importante para atrair o consumo e oportunidades de negócios.

Assim, neste artigo procuro enfocar aspectos da pesquisa realizada sobre a escuta do bolero entre imigrantes cubanos que vivem em São Paulo, trabalho financiado pela FAPERJ em forma de bolsa de Pós-Doutorado Sênior realizado junto ao PPG Música da UNIRIO entre 2012/2013(3).Esta investigação usa como metodologia 1) a etnografia em locais de encontros e festas destes imigrantes, perfazendo uma etnografia das práticas musicais (4); 2) entrevistas em profundidade que trazem narrativas sobre a escuta do bolero no ambiente privado que são analisadas levando em conta as formas de dar sentido à identidade de si a partir das cançóes; 3) e análise dos usos das redes sociais feitas por este grupo na busca por divulgar seus eventos, festas, fazendo do entretenimento um mediador de redes de solidariedade e estratégias de visibilidade/ audibilidade. A partir destes três focos metodológicos, vai se percebendo a escuta de cançóes como porta de entrada para conhecer aspectos mais amplos da experiência migrante numa metrópole global, em que entretenimento, cultura midiática e cenários urbanos se imbricam.

\section{Etnografia e entrevistas - desafios e contribuições}

QJá há algumas décadas, a etnografia tem despertado olhares desconfiados por parte dos antropólogos que, incomodados pela autoridade que ela, de alguma maneira, representava, elaboraram severas críticas, desconstruindo sua pretensa neutralidade. Dentro da Antropologia norte-americana surge, em meados dos anos 1980, o livro organizado por James Clifford e George Marcus (1986), Writing Culture, que se tornou um marco deste debate, gerando ainda outros trabalhos que radicalizariam a crítica sobre a etnografia. Pareciam instigados pelas questóes advindas dos debates sobre Pós-Modernidade, em especial o trabalho de Lyotard e a postulação de que a época em que vivemos é aquela onde já não existem mais metanarrativas, onde os jogos de linguagem múltiplos e variados predominam numa sociedade fragmentária, na qual é impossível estabelecer regras gerais, e o Pós-Estruturalismo e suas noçóes de descentramento, fragmentação e desconstrução, bem como as noçôes de dialogia, 
polifonia e evocação que viriam da semiologia russa de Mikhail Bakhtin.

Os chamados antropólogos pós-modernos norte-americanos, que já vinham de uma tradição antropológica culturalista - cujo nome principal era Clifford Geertz - que ressaltava que a cultura seria uma teia de significados e um texto a ser lido, se apropriaram deste debate mais amplo de crítica da cultura e da ciência passando a tomar o próprio texto etnográfico como objeto de interpretação. Assim, observando os observadores e seus escritos (antropólogos em sua prática de pesquisa), as preocupaçóes destes etnógrafos (ou "meta-etnógrafos") recaíram sobre questôes relativas ao próprio processo de produção do conhecimento antropológico e sobre a autoria dos textos resultantes desse processo, advogando que, neles, deveria haver uma polifonia que fosse capaz de fazer emergir observador e observados, sujeito e objeto, sem hierarquias. Trazendo desde críticas ao modo de fazer etnografia, passando por críticas à escrita etnográfica, encarada como um gênero literário, até a desconstrução do ideal científico e, na esteira disso, da própria etnografia, a Antropologia PósModerna trazia para o centro do debate a defesa de uma postura humanista para o fazer antropológico, enfatizando o caráter provisório e parcial de toda análise cultural.

Dentre as muitas abordagens, a favor e contra, que surgiram na Antropologia a partir de então, uma nos chama atenção para os propósitos aqui buscados. A ênfase em algo chamado por George Marcus (1995) de etnografia "multi-local" ou "multi-situada", que nos parece útil para a compreensão dos grupos em fluxo, em trânsito, não organizados espacialmente num único lócus, de modo a articular o local com o sistema social mais abrangente. Assim, pesquisas interessadas em captar mudanças culturais em espaços e cidades globais precisam desenvolver estratégias empíricas e conceituais que levam em consideração pessoas e imaginários que ultrapassam lugares, fronteiras, mas que estabelecem conexôes em várias escalas, levando em conta que, o que ocorre num local está intimamente relacionado numa gama de redes e no intercruzamento de processos e práticas, mediaçóes, conexôes e circuitos. Esta perspectiva nos auxilia na compreensão dos imigrantes caribenhos em suas múltiplas formas de articulação, arranjos identitários e sentidos de pertencimento na cidade de São Paulo, levando-se em conta que o grupo analisado pode ser encarado pela ótica da diáspora, em que relaçóes transnacionais de identidade e sociabilidades fazem parte do cotidiano destas experiências migrantes, de vidas em trânsito, onde apenas um olhar e uma escuta multi-situada pode reconhecer em suas práticas formas de estar juntos, não organizadas e localizadas em bairros, associaçóes de imigrantes formalizadas, mas em redes mais ou menos dispersas de associação, envolvimento e sentimento de pertença, que se conectam, desconectam e voltam a se conectar em múltiplos arranjos e re-arranjos. Voltaremos a esta questão mais adiante.

Com preocupaçóes semelhantes, Ulf Hannerz (2007) debate o desafio de fazer etnografia em meio ao mundo global, trazendo à tona questóes como cultura transnacional, cosmopolitismo, fronteiras e fluxos. Segundo ele, estas três palavras-chave - flluxos, fronteiras, híbridos - tão usadas na Antropologia 
atual, não são novidade, uma vez que fazem parte das preocupaçóes da disciplina desde o seu início a questáo dos interstícios, das zonas de contato intercultural. Mas, partindo do que Fredrik Barth (1969) propunha já nos anos 1960 - ou seja, uma noção de cultura enquanto processo não de grupos isolados, mas na definição de cultura que se dá exatamente nas margens, nos limites entre as culturas, nos fluxos culturais, nas trocas, nos intercâmbios realizados sempre nas fronteiras, onde vão se forjando as identidades de maneira processual, selecionando, assimilando, desconstruindo e se apropriando de elementos culturais variados - Hannerz avança este debate acrescentando que a fronteira é o lugar que demarca a separação, mas que também une, sendo porosa. Sem esquecer da questão da dominação e do poder, das trocas desiguais entre os fluxos, o autor assevera que mesmo não sendo relaçóes sempre amistosas, há sempre um jogo, uma negociação, em que as identidades se re-atualizam, reproduzem-se e se reafirmam (CARVALHO, 2006). Desta maneira, Hannerz não desconsidera os limites locais de significação, mas ressalta que a discussão no campo da Antropologia deva se ampliar para além das perspectivas locais e particularistas, assumindo um cosmopolitismo metodológico para que se contemple a multiplicidade e as intersecçôes de territórios materiais e simbólicos que conformam a experiência humana na atualidade.

Em meio a este debate sobre o fazer etnográfico que se abre aos fluxos, em que as fronteiras identitárias e grupais não são nítidas e em que a questão urbana cosmopolita se faz presente, é que se insere o trabalho que venho realizando entre imigrantes em São Paulo. A pesquisa, que se iniciou em 2010, foi se realizando na visita, observação e conversas com imigrantes da América hispânica em situaçôes de festas e eventos musicais. Embora tivesse como foco os imigrantes de origem cubana, busquei investigar lugares de encontro de imigrantes "latinos" em geral. Estes eventos se deram por várias ocasiôes no Centro Cultural Rio Verde, localizado na Vila Madalena, área da zona oeste da cidade que concentra muita atividade cultural e boêmia. Estas festas/encontros são organizados com periodicidade trimestral (embora não seja algo rígido) por produtores culturais que têm investido na promoção de músicos cubanos que aqui vivem.

Um destes produtores - Pedro Bandera - é cubano e músico, professor de percussão e integrante do grupo de "cuban latin jazz" Pepe Cisneros e Cuba 07. Este grupo tem apenas um componente brasileiro e tem se apresentado em diversos lugares como bares, festas, centros culturais, clubes de jazz nesta região da cidade, tendo se apresentado inclusive na última edição da Virada Cultural de São Paulo, em 2013, em evento chamado "Pernancubanos" que buscou reunir no mesmo palco artistas de Cuba e de Pernambuco, destacando suas similaridades. Importante ainda ressaltar que, nestas apresentaçóes, bem como nas festas acima citadas, há a presença de cubanos e brasileiros em igual medida, compondo-se como um evento musical em que prevalece a apreciação da música em primeiro plano (conforme a fala de alguns entrevistados) e menos a questão de ser cubano, latino ou outra coisa. Levando em conta esta fala nativa, a música e não a etnicidade seria o mote do encontro; entretanto, isto ainda vem sendo pensado e desconstruído nos desdobramentos da pesquisa. 
Sobre este percussionista acima citado, Pedro Bandera, interessante perceber como se insere tanto no grupo Cuba 07, como também acompanha a cantora brasileira e filha de imigrante cubano, Marina de la Riva, que tem produzido um trabalho que mescla elementos de música brasileira e cubana (PEREIRA, 2012), o qual traz importantes elementos para se pensar numa escuta em trânsito, uma escuta nômade que gera uma musicalidade entrelugares (BHABHA, 1998). Percebe-se este trânsito dos músicos entre grupos, ora se apresentando separadamente, ora em arranjos de grupos que fazem e se desfazem nas trajetórias de outros músicos cubanos que vivem aqui, como Fernando Ferrer e Yaniel Matos (5). Embora de trajetórias musicais diversas, com formação mais erudita ou ligada à tradição da música popular cubana, estes sujeitos vivem numa espécie de rede em que se elaboram as experiências dos cubanos em São Paulo.

Entretanto, não estou pesquisando apenas os músicos, mas também os ouvintes não músicos. Daí a minha preocupação em, nestas festas e encontros, conversar também com a plateia, formada por brasileiros e imigrantes, encontrando ali tanto músicos como fotógrafos, professores universitários, pesquisadores da área de Biologia, cineastas, entre outros. Por esta preocupação com os ouvintes não-especialistas em música, outro local de realização de etnografia tem sido os bares ou locais de dança autodenominados "latinos" ou cubanos, onde se toca salsa e merengue preferencialmente (e em menor escala bachata, rumba e pop latino). Há algumas casas como estas em São Paulo, tais como Azucar ou Rey Castro, que se situam em regiôes nobres da cidade, e atraem um público heterogêneo como turistas latinos em passagem por São Paulo, paulistanos interessados na música e cultura latina e cubana, bem como praticantes de dança de saláo, que recorrem a estes locais como forma de encontro e dança, obtendo descontos na taxa de entrada por pertencerem a escolas ou academias de dança de salão. Entretanto, nestes locais não foram encontrados em grande número os imigrantes caribenhos residentes, devido ao preço cobrado, bem como devido a uma certa pasteurização da música e da dança apontada por alguns de meus informantes.

Um outro lugar pesquisado e onde há mais frequência de imigrantes cubanos e colombianos, principalmente é o bar Conexion Caribe, também na Vila Madalena, que existe há quinze anos, tendo à frente Esteban Hernandez, proprietário da casa que se reveza como DJ, dançarino e mestre de cerimônias. Devo ressaltar que optou-se aqui por combinar a metodologia etnográfica com entrevistas em profundidade. Isso porque o tema em foco - a escuta do bolero - diz respeito à práticas de escuta e entretenimento que se dáo no ambiente privado, íntimo, por tratar-se de músicas que não são dançantes, alegres, mas dizem respeito aos sentimentos de dor, perda, saudade, desamor, etc., salientando elementos da compreensão da nostalgia como forma de entretenimento (6). Assim, a etnografia visa conhecer os lugares de encontro e sociabilidade dos imigrantes e suas formas de entretenimento e gosto musical mais amplos, mas para tratar das apropriaçóes trazidas pela escuta do bolero tem-se utilizado as entrevistas. Isso faz com que não se tenha aqui uma pesquisa sobre a recepção do bolero, uma vez que a recepção em si é um ato ou fenômeno que 
não ocorre na presença do pesquisador. O que se analisa, sim, são as narrativas sobre esta escuta, as memórias próximas ou distantes desta experiência, assumindo que temos assim a análise de uma narrativa memorialística em toda a sua complexidade, que envolve relaçóes entre real e imaginário, lembrança e esquecimento, aspectos voluntários e involuntários do ato memorioso, cargas de emotividade, aspectos subjetivos como a maior ou menor proximidade e relação de confiança com o pesquisador, entre outras variáveis.

A socióloga inglesa Tia DeNora (2000) traz importantes contribuições para pensar nas vantagens deste método e para a reflexão sobre a entrevista com ouvintes não-músicos como possibilitadora da compreensão sobre as subjetividades e sobre o uso da música (aesthetic reflexivity) como "tecnologia de si” (self technology), ou seja, como elemento de que lançam mãos os sujeitos para expressarem e construírem identidades, afetos, sentidos de auto-identidade (self identity) na vida social. Baseada em Giddens (1991), DeNora avança no debate sobre os sistemas peritos e reflexividade na modernidade e as formas de construção de subjetividade e de gestão da intimidade em contextos atuais, urbanos, cosmopolitas.

Pablo Vila (1996) nos ajuda a adensar esta reflexão quando discute as identidades narrativas construídas pelos ouvintes através e a partir da música. $\mathrm{O}$ autor fala em articulaçóes e interpelaçóes, e suas consideraçóes caminham de maneira próxima ao que tratamos aqui, ou seja, nas apropriaçóes diferenciadas e variadas com as quais os ouvintes elaboram sentido de si, identidades e visóes de mundo. Vila foca sua argumentação na questão da narrativa e seu uso teórico e metodológico, compreendida como categoria epistemológica e esquema cognitivo capaz de referir-se às formas com que atores sociais concretos se apropriam das cançôes e a partir disso, porque algumas formas de interpelação têm mais êxito que outras. Isso porque, nas narrativas, os indivíduos buscam construir um sentido, uma coerência para suas vidas, articulando passado, presente e futuro na forma de metas e desejos, construindo tramas argumentativas seletivas em que real e imaginário, memórias voluntárias e involuntárias, esquecimentos e silêncios se compóem de maneira complexa, trazendo à tona as construçóes identitárias nas quais as músicas exercem papel de artefato cultural privilegiado para as construçóes de si e dos outros.

Ao contar suas vidas, os ouvintes constroem-se como sujeitos de sua própria história, em que as cançóes entram como aportes para salientar aspectos, marcar fatos importantes, ajudar a compreender motivaçóes que os levaram a uma ação ou caminho e não outro, expressam o que buscam e almejam para sua vida privada, suas relaçóes amorosas, como também para sua vida em geral. No caso das cançóes românticas, traços melodramáticos sobre o amor, o sofrimento, a realização amorosa parecem estimulá-los a se encarar como sujeitos das emoçóes que os tomam, indivíduos que tem nestas narrativas musicais elementos para a construção de modelos de subjetividade e de narrativas de si, marcadas pela emotividade, é certo, mas que expressam aspectos das sensibilidades contemporâneas não só no âmbito privado, mas na esfera pública.

Mas, voltando ao bar Conexion Caribe, percebemos que neste local há a 
presença de muitos imigrantes não músicos, com os quais travei contato, mas que num primeiro momento, em sua maioria os cubanos, ficaram reticentes em conversar comigo e ainda mais em querer marcar entrevistas, sabendo que se tratava de uma pesquisa sobre imigrantes. A pergunta que me faziam, de início, era se não trataríamos de "assuntos políticos", ao que eu deveria assegurar que abordaríamos apenas questóes ligadas a música e cultura. Embora tendo em mente a convicção teórico-metodológica e ideológica de que estas duas dimensôes não se separam, concordava com as exigências colocadas e seguia a pesquisa. Este ponto me pareceu muito importante no trabalho etnográfico, uma vez que estamos lidando com grande número de imigrantes (embora não todos) em situação de ilegalidade no país, temerosos das implicaçóes que a exposição de suas vidas para uma pesquisadora desconhecida poderia ter. Entretanto, mesmo entre imigrantes já estabelecidos aqui há muito tempo e legalizados, este temor aparecia.

Foi assim que minha conversa com José Luiz, um senhor de 70 anos que trabalha nos finais de semana como garçom e porteiro no bar Conexion Caribe, encaminhou-se. Em sua fala, ali mesmo no bar, mais para o fim da noite, quando o local já estava quase vazio, contou-me sobre os vinte anos em que está no Brasil, casado com uma brasileira e morador do bairro de Higienópolis. Narrou sua trajetória de vida pontuada por cançôes e lembranças de juventude (que cantava durante a conversa) articulada ao trabalho, enfatizando cada ocupação que teve, de servente de pedreiro, garçom, até ter participado com orgulho da construção dos Centros Educacionais Unificados (CEUs) durante a prefeitura de Marta Suplicy em São Paulo (2001-2004), enfatizando ser a sua uma vida de luta. Descrevia em detalhes os trajes que usava quando jovem em Havana para ir aos bailes e festas dançantes, cantando boleros pela rua. Quando lhe pergunto sobre alguma canção em especial, ele não se lembra de nenhuma em particular, mas das cançóes de César Portillo de la Luz, e se emociona, dizendo que o amor proibido entoado nas cançóes evocava nele a sua terra natal, para ele proibida hoje, traçando um paralelo entre o impedimento amoroso e o impedimento do regresso a Cuba, por razóes que ele não quis contar em longos silêncios reveladores.

Desta narrativa de Jose Luiz, algumas coisas chamam atenção e devem ser sempre consideradas. Entre elas, destaco o fato de que não pôde ser feita uma entrevista em profundidade com a metodologia de história de vida, em que o sujeito tem tempo e que é feita em local tranquilo, privado, com a intençáo de narrar os fatos de sua vida numa narrativa coerente, dando sentido a sua trajetória, como era num primeiro momento intenção de minha pesquisa. Os fatos narrados vinham a sua memória em flashes de acontecimentos, de forma descontínua e fragmentada. Não quero com isto dizer que estas memórias são menos válidas ou menos confiáveis; ao contrário, pareceram-me de uma riqueza ímpar, trazendo afetos, sentimentos e experiências acionadas pela música. Sugiro apenas que a pesquisa teve de se adaptar a situaçóes e realidades próprias ao universo pesquisado, em que as situaçóes de contato são mais fluidas, fragmentadas, mas em que o informante/depoente/sujeito memorialista também exerce sua capacidade narrativa de dar sentido à sua identidade e suas 
experiências vividas.

O antropólogo espanhol Francisco Cruces (2003) usa a designação "etnografias sem final feliz", ao falar das experiências de pesquisa realizadas em cidades globais ou cosmopolitas, nas quais se torna um desafio encaminhar etnografias em contextos onde o fluxo de pessoas, saberes, significados parecem corroer o sentido fechado, localizado e comunitário de cultura. Tive a princípio uma certa dificuldade em encontrar estes imigrantes, uma vez que não se encontram em comunidades organizadas como as imigraçôes dos inícios do século XX se estabeleceram em São Paulo. Há uma certa ideia, que prevalece em certa Antropologia mais tradicional, de encontrar as comunidades de imigrantes em bairros fixos (por exemplo, italianos no Bixiga, japoneses na Liberdade), organizados por laços de vizinhança, religiosidade, parentesco, em que o grupo parece estar ali pronto à espera do pesquisador. $\mathrm{O}$ que a pesquisa com este grupo cubano tem mostrado é que há, sim, uma ligação de pertença entre eles, mas ela se dá de maneira mais fluida, que envolve vários pertencimentos (de etnia, classe, profissáo) e se encontram mais ou menos dispersos pela cidade. A etnografia, assim, deve levar em conta esta singularidade náo anulando ou desmerecendo o grupo estudado como uma "comunidade", mas como um grupo que vive em redes de solidariedade, apoio mútuo e sentimento de pertença a uma comunidade imaginária que não estabelece vínculos de maneira tradicional, local, mas multi-local e multi-situada (MARCUS, 1995), em seus fluxos e fronteiras híbridas (HANNERZ, 1997).

Isto tem se mostrado um desafio para a pesquisa, mas também um ponto a favor do próprio trabalho etnográfico que deve se adaptar, criar métodos e conceitos próprios a cada realidade estudada, sem partir de princípios apriorísticos e fechados, mas contando com a sensibilidade do pesquisador em atribuir significação às representações e práticas nativas, aonde as teorias e metodologias vão se elaborando, fazendo-se e refazendo-se a partir da experiência do campo, ajudando a criar conceitos condizentes sobre o que se quer compreender. Retomando a metáfora de Cruces, seria uma etnografia sem final feliz, se isto significar portos seguros e certezas, mas com final feliz, sim, por nos forçar a rever conceitos como cultura, lugar, comunidade, grupos migrantes. Mais ainda, mostrando sua permeabilidade às lógicas díspares dos agentes (como por exemplo, sentir-se em comunidade e não sentir-se em outros momentos; acionar o grupo e tê-lo como referencia em alguns momentos e em outros não), o caráter situado e provisório do conhecimento que produzimos, e os múltiplos pertencimentos urbanos e transnacionais que estes sujeitos migrantes experimentam, vai se esboçando onde residem as maiores virtudes da etnografia como método para entender as imbricações, cruzamentos e matizes da cultura contemporânea.

Chamo ainda a atenção para um fato já descrito, mas que merece maior atenção, que é o fato de esta prática ocorrer em uma grande cidade, que pode ser chamada de global. A produção global de localidades vem sendo forçada a ser repensada no sentido do que Appadurai (1997) chama de translocalidades, no qual muitas cidades podem estar assumindo esta designação ao 
comportarem processos econômicos globais e fluxos de culturas e povos em trânsito que, se não as divorciam da nação em que estão inseridas, problematiza as noçôes políticas de território, trazendo à tona uma questão cultural de afiliação mais ampla.

\section{Migrações, mídias, entretenimento}

LComo já comentado, o panorama das migraçôes contemporâneas apresenta um quadro diferente daquelas do final do século XIX e início do século $\mathrm{XX}$. As migraçóes na atualidade ocorrem num espaço globalizado, inserido nas novas condiçóes de um mundo onde as atividades econômicas ocorrem em ambiente global e sistêmico, e onde a cultura da mobilidade foi completamente integrada à experiência individual e coletiva, materializando formas de vida em espaços múltiplos, de geometria variável, num repertório de competências amplamente compartilhado (PERALVA, 2007).

Por isso, os estudiosos do fenômeno migratório têm nomeado as migrações contemporâneas como um fenômeno transnacional (COGO, 2010), para além da noção de sociedade ou territorialidade confinada nos limites do Estado-Nação, salientando a experiência da simultaneidade em que vivem os povos em trânsito dentro e fora das fronteiras políticas nacionais. Esta abordagem transnacional permite compreender as realidades, imaginários e cotidianos destes povos e seus descendentes que mantem com a terra de origem laços persistentes em redes sociais que se estendem para além das fronteiras nacionais, assim como se integram e possuem sentimento de pertença com as novas localidades escolhidas para se viver (PEREIRA, 2013). Estes laços transfronteiriços em que estão inseridos estes grupos migrantes são típicos de uma era de capitalismo tardio em que a realização de negócios, remessas de dinheiro, uso dos meios de comunicação social, participação política, práticas religiosas, a escuta e prática de gêneros musicais, entre outros aspectos, ajudam a atar estes laços transnacionais, estas redes de ligaçáo e contato, forçando a que se repense a noçáo de sociedade sem partir do pressuposto das fronteiras nacionais (LEVITT e GLICK SCHILLER, 2010), e reconhecendo nos suportes tecnológicos atualmente mobilizados nas comunicaçôes à distância - garantindo a instantaneidade dos contatos virtuais - elementos que reconfiguram as relaçóes entre espaço e tempo.

Desde a década de 1990, o antropólogo Arjun Appadurai (2004) já vem chamando estes espaços sociais transnacionais de "esferas públicas de diáspora” no enfoque dado por ele à dimensão cultural da globalização. Embora lembre que os Estados nacionais ainda sejam extremamente relevantes, argumenta que a vida social náo se encontra confinada nos seus limites, graças a dois elementos interconexos e diacríticos que, segundo ele, caracterizam a atualidade, a saber, as migraçóes e os meios de comunicação eletrônicos, os quais vem exercendo um efeito conjunto no funcionamento da imaginação global e do conhecimento do Outro em escalas nunca antes vistas, gerando características próprias da subjetividade moderna em um fluxo incessante de pessoas, capitais, informaçóes midiáticas que ele definiu em cinco categorias (scapes): mediapaisagem, etnopaisagem, financiopaisagem, ideopaisagens, tecnopaisagens. $\mathrm{O}$ 
funcionamento da imaginação, neste sentido, não se coloca como puramente emancipatório e nem totalmente disciplinado, mostrando-se como um espaço de negociação, contestação, diálogo em que os grupos inserem os elementos globais em seu cotidiano e nos usos que fazem das redes sociais e midiáticas das quais se apropriam.

Denise Cogo (2010) enfatiza que um dos processos da atualidade que tem modificado a comunicação transnacional e suas configuraçóes de cidadania é a intensificação das redes sociais virtuais que extrapolam dinâmicas locais e nacionais sem se desvincular delas, mas que aciona intercâmbios solidarísticos - mais do que formas de organização coletiva centralizadas - que se denominariam "redes de comunidades virtuais identitárias" (p. 42). Nestas, a comunicação midiática vem se revelando como um espaço estratégico de cidadania para as redes de imigrantes, no intuito de se contrapor ou obter espaços alternativos aos discursos midiáticos hegemônicos. Estas construçóes de discursos e narrativas no Facebook, por exemplo, por parte dos imigrantes cubanos que tenho acompanhado, revela um misto de lógicas que tanto acionam imaginários já consolidados pela memória midiática hegemônica (Caribe e Cuba associados a uma latinidade de corpos, danças, alegria e brejeirice) como também em dinâmicas de rememoração dos indivíduos em narrativas múltiplas e diversas que não necessariamente seguem a lógica dominante e estereotipada sobre o Caribe.

Não adentrarei nem explorarei mais este aspecto no espaço desta comunicação, mas aponto apenas o papel destas redes virtuais de comunicação em que se divulgam eventos e apresentaçóes musicais, se expóem posicionamentos políticos e se projetam estratégias de visibilidade e identidade destes grupos para além dos imigrantes, mas integrando brasileiros e outras nacionalidades em ágoras por onde circulam, negociam, chocam-se e se re-arranjam imaginários diversos. Estas estratégias de visibilidade e audibilidade ocorrem muitas vezes pela via do entretenimento, que surge como elemento importante aglutinador de anseios, afetos, reivindicaçóes de identidade, pertença e cidadania na esfera pública intercultural e diaspórica em que vivemos. Percebemos neste processo uma inventividade de táticas que relacionam blogs, fanpages, bares, restaurantes que se articulam na divulgação de eventos e práticas, acionando agentes variados nestas redes de pertencimento. Como sugere Denise Cogo, se estabelece uma.

(...) economia transnacional das migraçóes, na reprodução e sustentabilidade dos usos tecnológicos que se desdobram em iniciativas solidarísticas das migraçóes. Muitas das práticas de comunicação cidadã, como jornais e websites se mantêm, por exemplo, com recursos advindos do chamado comércio étnico (bares, restaurantes, casas noturnas, músicas, agências de turismo, etc.), muitas vezes, de pequeno porte, assim como retroalimentam esse comércio atribuindo a ele visibilidade e colaborando para construir redes voltadas ao seu consumo. (COGO, 2010, p.60, grifos meus).

Retomando a nomenclatura de Appadurai, temos também as mediapaisagens como relatos de realidade centrados em imagens e sons. 
Os meios de comunicação emergem como grandes possibilitadores de contatos pessoais, de imagens da terra de origem e de sons e músicas que vêm de longe, da terra natal, mas que se atualizam na escuta feita hoje, construindo mundo reencontrados, reconstruídos. Desta maneira, a música caribenha, seja em suas versôes alegres, dançantes, festivas ou em seu cunho melancólico, nostálgico e triste, aciona imaginários e práticas que têm no entretenimento seu canal de expressão, divulgação, resistência, engajamento, adaptação, tornando mais clara a acepção política das cançôes românticas e do próprio entretenimento, destacados no início deste texto.

sono stati bloccati da alcuni manifestanti che non voglio nessuna modifica allo stato attuale del luogo. I conflitti interni alla società berlinese circa le destinazioni d'uso degli spazi assegnati alla memoria dopo l'abbattimento del Muro sono il sintomo della complessità del processo di elaborazione del trauma della divisione e della riunificazione.

Una certa funzione pratica di separazione con le rive della Sprea, il Muro della East Side Gallery la svolge ancora oggi: accade così che la parte del Muro che si affaccia sulla strada sia la superficie che costituisce la galleria a cielo aperto mentre la parte che si rivolge al fiume sia stata oggetto di scrittura anonima (fig. 10). Lo spazio che circonda la riva si configura come un corridoio verde dotato di punti di ancoraggio per godere del suggestivo panorama, mentre più in là in direzione del ponte di Oberbaum troviamo alcuni bar (fig. 11) e persino una spiaggia (fig. 12). Quella che una volta era la Striscia della Morte oggi è un luogo di relax, di svago, di spensieratezza: come accade in un altro famoso parco di Berlino, il Mauerpark, è possibile anche qui sedersi a terra e sfruttare il Muro per appoggiarvi

la schiena (fig. 13). Sebbene siano presenti ancora dei terrain vague (fig. 14) dovuti all'incompletezza dei progetti di riqualificazione e alla particolare caratteristica della città di essere sempre un cantiere aperto, la vera vittoria dei berlinesi sul dolore del Muro più che la galleria a cielo aperto è la fruizione di questa area verde che d'estate diventa ancora più movimentata.

Nonostante il Muro di Berlino sia stato abbattuto 24 anni fa, mantiene qui la sua funzione divisoria: separa uno spazio prettamente turistico, quello della East Side Gallery, da uno spazio del quotidiano, l'area verde a ridosso della Sprea.

Se non mancano anche in questo spazio i deittici memoriali come le colonnine informative che ritroviamo in molte delle zone segnate dalla Mauerweg (4), il superamento della memoria traumatica ci sembra che avvenga qui con le stesse strategie di neutralizzazione del trauma che ritroviamo a Mauerpark: si tratta di una valorizzazione ludica del luogo che funziona, come abbiamo visto, al pari di un'erma bifronte. Il lato che dà sulla strada cattura l'attenzione dei turisti per le sue dimensioni e i suoi colori, il lato sulla Sprea restituisce ai cittadini un luogo di svago ad essi sottratto durante l'era della divisione. 
La storia che il Muro di Berlino ci racconta non finisce però qui: superato l' Oberbaumbrücke ci addentriamo nel cuore dell'Est, a Friedrichshain, oggi sede di MTV Berlin, della Universal, della Labels Berlin e dell'hotel Nhow, l'unico hotel al mondo dotato di studio di registrazione. Il perché queste importanti istituzioni nel campo musicale abbiano scelto di posizionare le loro sedi in questa zona è abbastanza semplice: abitare in quella che una volta era la parte Est della città, come abbiamo ribadito nel terzo capitolo, è diventato di tendenza, specie per un certo ambiente berlinese, lo stesso che ha trasformato l'Ostalgie in una forma di vita.

Il quartiere, dall'arena $\mathrm{o} 2$ agli studi di una delle più importanti etichette discografiche al mondo, sembra essersi dunque consacrato alla musica (e ciò spiega la scelta del regista di Berlin Calling, Hannes Stöhr, di girare la scena della crisi di Ickarus a ridosso del Muro della East Side Gallery). La cosa che stupisce l'osservatore è che gli edifici che ospitano il Nhow e la sede della Universal, dotati anch'essi di una terrazza sulla Sprea, hanno ricreato in piccolo una sorta di East Side Gallery ad uso e consumo dei propri clienti. Alcune lastre del Muro, simili a quelle che troviamo al Checkpoint Charlie e sparse in altri punti della città, sono state collocate sulla terrazza e affidate nel restyling ad artisti contemporanei (fig. 15). La mostra, per di più, ha il vantaggio rispetto alla East Side Gallery di venire costantemente rinnovata con opere diverse e nel periodo delle nostre osservazioni un'opera ha particolarmente colpito la nostra attenzione per il suo carattere di denuncia - seppur ironica - verso un altro muro tristemente celebre, quello del Mexico, soprannominato "Muro de la tortilla" (fig. 16).

Il Nhow Hotel, edificio completamente restaurato dall'architetto tedesco Sergei Tchoban ed arredato dall'archistar Karim Rashid, è considerato uno degli edifici più glamour della città ed è «il primo hotel in Europa in cui tutto ruota intorno ad arte, musica e design, l'ospitalità che meglio interpreta lo spirito della città: artistica, espressiva, creativa» (5). All'ingresso della struttura, oltre ad una N formato gigante dal colore fuxia, simbolo della catena di hotel, si trova un pezzo di Muro dipinto (fig. 17) che si sostituisce al simbolo di Berlino più conosciuto, l'orso, che in genere accoglie i turisti all'ingresso degli hotel. All'interno dell'hotel, poi, l'isotopia tematica del Muro di Berlino non smette di essere presente: la sala che funge da discoteca ha al suo interno la riproduzione pop del Berliner Mauer in cartongesso (fig. 18).

Questa ridondanza tematica della presenza del Muro all'interno dell'hotel, che sul piano figurativo è contraddistinta da una veste pop e glamour, fa parte di un processo più profondo di reinserimento dei discorsi sul Muro all'interno di un vasto discorso sull'identità di Berlino: il Mauer è diventato un logo della città (al pari dell'orso) ma ne deve significare l'identità cangiante e multiforme. Ecco perché viene ridipinto, diventa supporto espressivo per veicolare messaggi di pace o di denuncia: il suo abbattimento nel 1989 non ne ha segnato la scomparsa.

La semiosfera non ha fatto che reinserirne le tracce all'interno dei propri discorsi, finendo per farlo diventare uno dei testi privilegiati della cultura berlinese. 
La versatilità significante del Muro ha fatto sì che esso sia diventato tutto e sia stato posto da per tutto: diviso, perdendo la sua funzione di barriera (o talvolta mantenendola, come abbiamo visto) è diventato uno degli oggetti più presenti nella vita dei berlinesi, dall'arredo urbano al souvenir. Del resto, il saggio Grass, nel suo È una lunga storia (1995, pag. 10), fa dire a Fonty: «Il frammento è meglio dell'insieme!» e quanto accade sulle rive della Sprea sembra confermarlo.

\section{Referências Bibliográficas}

APPADURAI, Arjun. Dimensôes culturais da globalização. Lisboa: Teorema, 2004.

. "Soberania sem territorialidade: notas para uma 
geografia pós-nacional”. Revista Novos Estudos CEBRAP. n.49. nov/1997.

BARTH, Fredrik (dir.). Ethnic Groups and boundaries: the social organization of culture difference. Oslo: Norwegian University Press, 1969.

BHABHA, Homi. O local da cultura. Belo Horizonte: Ed. UFMG, 1998.

CARVALHO, Francismar. "Fronteiras e zonas de contato: perspectivas teóricas para o estudo dos grupos étnicos”. Dimensóes. vol. 18. 2006. pp. 49-70.

CLIFFORD, James MARCUS, George (ed.). Writing Culture: The Poetics and Politics of Ethnography. University of California Press, 1986.

COGO, Denise. "Comunicação, cidadania e transnacionalismo". In: BARBALHO, Alexandre et alli. (orgs.). Comunicação para a cidadania: temas e aportes teórico-metodológicos. São Paulo: INTERCOM, 2010.

CRUCES, Francisco. "Etnografías sin final feliz. Sobre las condiciones de posibilidad del trabajo de campo urbano en contextos globalizados". Revista de Dialectología y Tradiciones Populares. vol 58, n. 2, 2003. Disponível em: <http://rdtp.revistas.csic.es/index.php/rdtp/article/ viewArticle/154> Acesso em mai. 2013

DENORA, Tia. Music in everyday life. United Kingdom: Cambridge Univesity Press, 2000.

GIDDENS, Anthony. Modernity and Self-Identity: Self and Society in the Late Modern Age.

Stanford University Press, 1991.

HANNERZ, Ulf. "Fluxos, fronteiras, híbridos: palavras-chave da Antropologia transnacional”. Mana. 3 (1), 1997. pp. 7-39. Disponível em:

<http://www.scielo.br/pdf/mana/v3n1/2454.pdf> Acesso em jul. 2013

HUIZINGA, Johan. Homo Ludens - o jogo como elemento da cultura. São Paulo: Ed.Perspectiva, 2008.

KNIGHTS, Vanessa. "Tears and screams: performances of pleasure and pain in the bolero". Texto apresentado na 12th Biennial Conference of the International Association for the Study of Popular Music (IASPM). Montréal/Canada, Julho/2003.

LEVITT, Peggy e GLICK SCHILLER, Nina. “Conceptualizar a simultaneidade: uma visão da sociedade assente no conceito de campo social transnacional”. In: MARQUES, M. Margarida (coord.). Estado-Nação e migraçóes internacionais. Lisboa: Livros Horizonte, 2010.

MARCUS, George. "Ethnography in/of the World System: The Emergence of Multi-Sited 
Ethnography”. Annual Review of Anthropology. Palo Alto, California, vol.24, 1995. pp. 95-117.

MORIN, Edgar. Cultura de massas no século XX: o espírito do tempo I - Neurose. Rio de Janeiro: Forense Universitária, 1976.

PERALVA, Angelina. 2007. Globalização, migrações transnacionais e identidades nacionais. Disponível em <http://www.fflch.usp.br/sociologia/posgraduacao/sites/trajetorias/txts/globalizacao_migracoes_ transnacionais_e_identidades_nacionais.pdf $>$. Acesso em: inserir data.

PEREIRA, Simone Luci. "À Escuta do Bolero: memória, identidade e gêneros musicais na dinâmica dos fluxos locais e globais". In: TEJEDA, Dario e YUNEN, Rafel Emilio (orgs). El bolero en la cultura caribeña y su proyección universal. Santo Domingo: INEC, 2010.

. "Migraçôes, mundialização, cultura midiá-

tica”. In: VALENTE, Heloisa (org.). Trago o fado nos sentidos - cantares de um imaginário atlântico. São Paulo: Letra e Voz, 2013.

STOKES, Martin. The republic of love: cultural intimacy in Turkish popular music. Chicago/EUA: University of Chicago Press, 2010.

TRIGO, Luiz Gonzaga. Entretenimento: uma crítica aberta. São Paulo: Ed. SENAC, 2003.

VILA, Pablo. "Identidades narrativas y música - una primera propuesta para entender sus relaciones. TRANS (Revista Transcultural de Música - Transcultural Music Review). n. 2, 1996.Disponível em: <http://www. sibetrans.com/trans/a288/identidades-narrativas-y-musica-unaprimera-propuesta-para-entender-sus-relaciones> Acesso em jan. 2013.

\section{NOTAS}

(1) Este texto é uma versão ampliada da comunicação apresentada na Mesa-Redonda

“Música, Entretenimento e Culturas Urbanas”, um diálogo dos Grupos de Pesquisa 
Comunicação e Culturas Urbanas e Música e Entretenimento, no XIII Encontro dos Grupos de Pesquisa em Comunicação, evento componente do XXXVI Congresso Brasileiro de Ciências da Comunicação, ocorrido em Manaus/AM, em setembro de 2013.

(2) Como exemplo, HUIZINGA, 2008.

(3) A pesquisa continua nos anos 2014/2015, abrangendo uma etnografia de práticas musicais não apenas de cubanos, mas outros imigrantes provenientes da América Latina que vivem em Sáo Paulo. Esta pesquisa se realiza junto à Linha de Pesquisa "Contribuiçóes da Mídia para a Interação entre Grupos Sociais", no Programa de Pós-Graduação em Comunicação e Cultura das Mídias (Mestrado e Doutorado) da UNIP - Universidade Paulista.

(4) Por práticas musicais entendemos tanto as atividades de músicos, cantores, produtores musicais como também a escuta de cançóes, a participaçáo e frequência em shows, eventos, bares e locais de dança, articulando produtores e receptores.

(5) No início de 2014 outro grupo musical se formou - o Batanga \& Cia - com músicos cubanos que já fazem parte de outros grupos e numa proposta de resgatar cançôes, ritmos e gêneros musicais cubanos dos anos 1930/40/50 (como danzón, batanga, son, cha cha cha, rumba, bolero, dentre outros). Apresentaram-se pela primeira vez em fevereiro/2014 numa festa chamada "Vila Latina" (ocorrida no Centro Cultural RioVerde), que reúne periodicamente apresentaçóes musicais ao vivo, Djs, aula de danças caribenhas como salsa e merengue, exibição de filmes e debate com diretores, exposiçóes de artistas cubanos, venda de comidas e bebidas cubanas, perfazendo um circuito de divulgação e promoção da cultura "latina” em S.Paulo.

(6) Sobre a ideia de uma "indústria da nostalgia", na qual um certo revival do bolero nos anos 1990 se insere, ver KNIGHTS, 2003. Sobre a escuta do bolero em meio à cultura global, ver PEREIRA, 2010. 